\title{
Measuring Political Commitment to Reducing Hunger and Under-nutrition: Can it be Done and Will it Help?
}

\author{
Dolf J.H. te Lintelo
}

Abstract Food justice in India requires stronger governance and greater political commitment. This article
introduces the Hunger Reduction Commitment Index (HRCl): a novel approach to assess governments'
political commitment to reduce hunger and malnutrition. Cross-country comparisons and within-country
analyses aim to demystify what such commitment may look like, in order to foster accountability and to
provide practical policy directions for civil society, donors and governments. Unlike other hunger indices that
typically compare outcomes, the HRCl ranks government efforts. It uses secondary data on three dimensions:
policies and programmes; public expenditures; and legal frameworks. In addition, expert perception surveys
conducted in Bangladesh and Zambia provide indications on what aspects of political commitment these
governments do well, or less well. The HRCl 2011 is topped by Malawi. India takes thirteenth spot out of
21 developing countries, with a medium level of political commitment.

\section{Introduction ${ }^{1}$}

The persistence of widespread hunger and malnutrition in India, despite high and enduring economic growth, continues to fuel academic and policy debates. These emphasise the magnitude of the problem; its pace and direction of change over time; its location; the groups afflicted, and increasingly, the role of governance. Hunger and malnutrition reduction in India requires stronger governance at all levels of administration, in terms of service delivery, accountability and responsiveness to citizens' needs, and greater availability of high-quality data (Haddad 2009). A lack of horizontal (between ministries) and vertical (between Central/State and local governments) coordination; bureaucratic focus on inputs and outputs rather than outcomes; low budget allocations; leakages and weak targeting hinder improved nutrition outcomes (Mohmand 2011). Further questions remain about the political commitment of India's leadership. The Government of India has stated its desire to act; most memorably when Prime Minister

Manmohan Singh labelled malnutrition a national 'curse' in his 2008 Independence Day speech. While such public statements demonstrate critical leadership, they may yet have mere symbolic value. A better assessment of political commitment needs to look beyond rhetoric; after all, action speaks louder than words.

Accordingly, this article presents the Hunger Reduction Commitment Index (HRCI), a novel approach to assess governments' political commitment to reduce hunger and malnutrition. The HRCI demystifies what such commitment may look like and fosters accountability through cross-country comparisons and within-country analyses.

Existing hunger indices such as the Global Hunger Index measure outcomes, and are limited in serving as an accountability mechanism. ${ }^{2}$ This is because a multitude of factors contribute to hunger and malnutrition reduction, many of which governments cannot control, such as exclusionary social norms or insanitary practices within households and communities, or a sudden economic crisis. Moreover, limited transparency means that it is difficult to know what governments are doing to address the situation. When outcome trends improve, governments can claim credit (perhaps falsely) and when they trend badly, governments

IDS Bulletin Volume 43 Number S1 July 2012 @ 2012 The Author. IDS Bulletin (c) 2012 Institute of Development Studies Published by Blackwell Publishing Ltd, 9600 Garsington Road, Oxford OX4 2DQ, UK and 350 Main Street, Malden, MA 02148, USA 


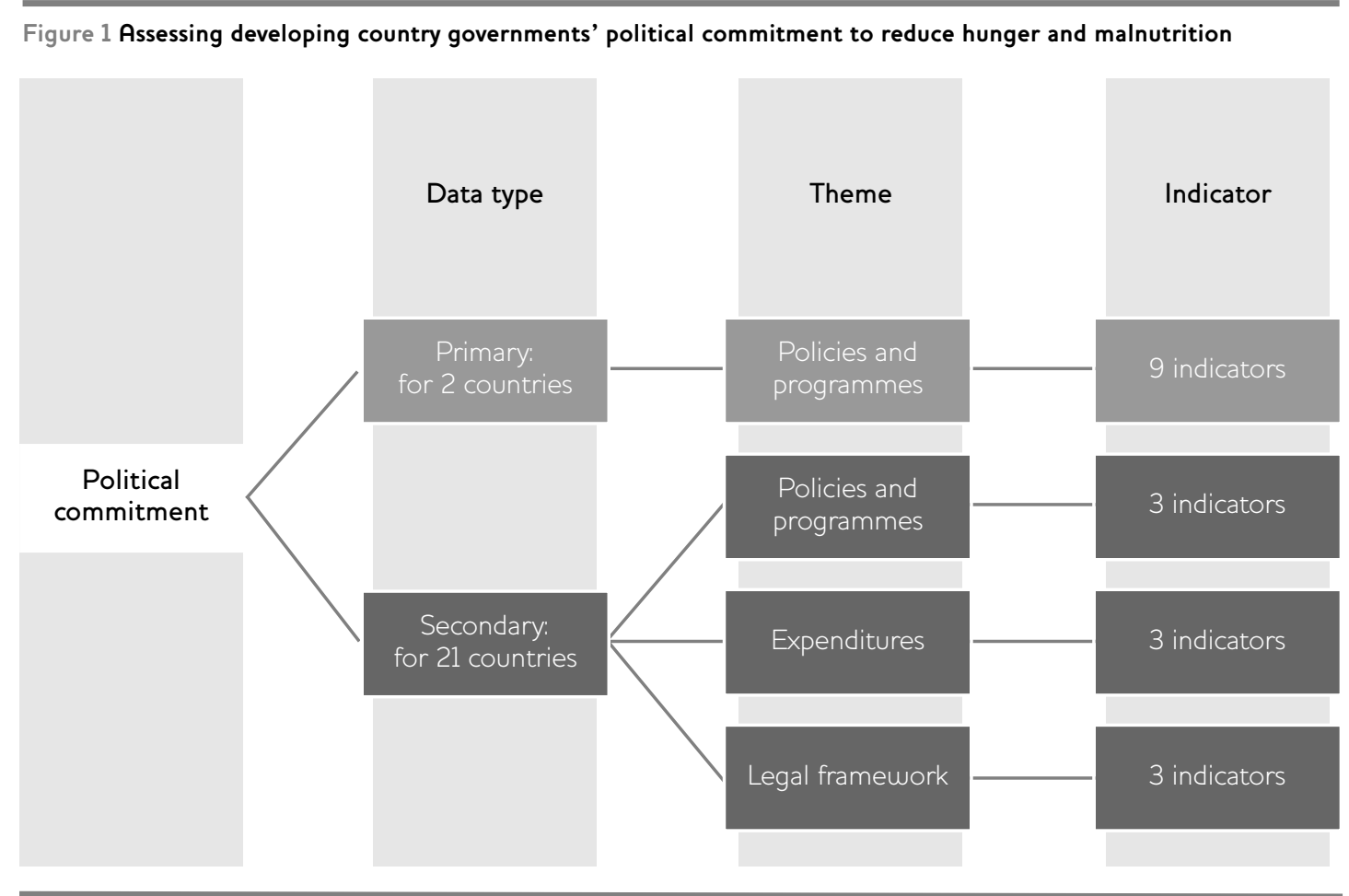

get the blame (perhaps unfairly). The HRCI hence aims to track a government's commitment, in a manner that is credible, sensitive to government action, achievements and failures and able to measure progress or regress over time. Greater transparency will enable civil society organisations to hold governments to account and to keep hunger and malnutrition higher on development agendas. Indian civil society already has a strong track record pursuing food justice. Notably, the Right to Food Campaign has been instrumental in developing the Mahatma Gandhi National Rural Employment Guarantee Act (2005), whose initiation of a right to 100 days of employment per annum enhances incomes and access to food. Civil society has also been intimately involved in developing (amongst others) the National Food Security Bill (2011) and in reforming flagship programmes such as the Targeted Public Distribution System and the Integrated Child Development Services. The HRCI aims to support such efforts, but also suggests priorities and aids governments to track existing efforts and to hold themselves to account. Finally, by making political commitment more transparent and linking this to more effective government action, $\mathrm{we}^{3}$ propose that over time, greater commitment will lead to better hunger and malnutrition outcomes.

\section{Conceptualising political commitment to reduce hunger and malnutrition}

In common parlance and academic debates 'political will' tends to be equated with 'political commitment', so we use the terms interchangeably. Political will/commitment is the 'slipperiest concept in the policy lexicon' (Hammergren 1998: 12); it is vague, lacks analytical content, yet is routinely used in a catch-all (Thomas and Grindle 1990: 1164) or post-hoc tautological manner (Brinkerhoff 2000). Our searches failed to identify efforts that measured or systematically compared political commitment/will across or within countries.

How then to conceptualise commitment in a way that facilitates its measurement? Building on Brinkerhoff (2000), political commitment can be broken down into components of action and intention. Commitment has a latent quality: even in the absence of action, there may be a residual and intangible element of intention. For example, decision-makers' assessments of their capacity to implement new policies and the strength of opposition to it will influence their a priori willingness to make commitments (Morrissey and Verschoor 2006, in Brinkerhoff 2007). The difficulty of identifying intention leads us to focus analysis on government actions. One way of thinking about 
Table 1 Nine secondary data indicators by dimension of food security and sector, developing countries

\begin{tabular}{lllll}
\hline & Food and agriculture & $\begin{array}{l}\text { Women's } \\
\text { empowerment }\end{array}$ & Social protection & Health environment \\
\hline Food availability & $\begin{array}{l}\mathbf{1} \text { Public expenditure } \\
\text { on agriculture }\end{array}$ & $\begin{array}{l}\mathbf{5} \text { Women's access } \\
\text { to agricultural land }\end{array}$ & \\
Food access & $\begin{array}{l}\mathbf{4} \text { Implementation of } \\
\text { FAO National }\end{array}$ & $\begin{array}{l}\mathbf{2} \text { Public expenditure } \\
\text { on education }\end{array}$ & $\begin{array}{l}\mathbf{7} \text { Constitutional right } \\
\text { to social security }\end{array}$ & $\begin{array}{l}\mathbf{6} \text { Civil registration } \\
\text { Programme for Food } \\
\text { Security }\end{array}$ \\
& & & $\begin{array}{l}\mathbf{8} \text { Constitutional } \\
\text { protection of the right } \\
\text { to food }\end{array}$
\end{tabular}

Food utilisation

3 Public expenditure

on health

Note Indicator 9 - 'The existence of a national hunger or nutrition strategy' covers all cells of table.

this is to consider what governments say, what they do, and what they do not do. Actions of particular interest concern sustained material, legal and financial efforts (The Policy Project 2000).

Consequently, we identify three themes under which government action is compared across a selected group of developing ${ }^{4}$ countries: (a) policies and programmes, (b) legal frameworks, and (c) public expenditures. This conceptualisation is potentially applicable to a range of issues well beyond hunger and malnutrition.

We employ secondary data to calculate index scores for a set of 21 countries. For two of these, Bangladesh and Zambia, we also use primary data. Figure 1 provides an overview of the HRCI activities, which are discussed in further detail below.

\section{Building the $\mathrm{HRCl}$ using secondary data}

Hunger, malnutrition and the commitment to fighting these are imprecise concepts that can be approximated by several variables. Hunger and malnutrition are complex phenomena driven by amongst others social, biophysical and political economic factors, and thus offer a wide range of entry points for government intervention: for example, on agriculture, social protection, health, women's empowerment, poverty reduction, etc. We select three indicators for each of our (a) policies and programmes, (b) public expenditures and (c) legal frameworks themes. Indicator selection is neither prescriptive nor exhaustive. It is theory-based, dependent on data availability, and indicators should:
- cover major aspects of efforts to reduce hunger: food availability (production and market availability), food access (e.g. through (subsidised) purchases or through leveraging of entitlements) and food utilisation (the ability to use food to build nutrition status);

- be simple and transparent;

- be highly correlated within, but not across themes.

Moreover, although political commitment should drive hunger outcomes and vice versa, the difficulty of attributing outcomes to government (in)action alone means that we do not use hunger outcome indicators in calculating commitment scores. Instead, we present commitment rankings within the context of country-specific hunger levels.

Table 1 sets out the selected indicators for which we collected secondary data, organised by sector (data sources are given in: te Lintelo et al. 2011).

\section{Policies and programmes}

For this theme, three indicators are selected:

- Does a government have a national hunger and/or nutrition policy or strategy? The existence of national policies and strategies signals a government's recognition of hunger as a problem that needs addressing, and to steer government action across administrative levels.

- Implementation of FAO National Programme for Food Security. The Food and Agriculture Organization (FAO) assists a wide range of 


\begin{tabular}{|c|c|c|c|c|c|}
\hline Country & $\begin{array}{l}\text { Policies and } \\
\text { programmes } \\
\text { (a) } \\
\text { (high score is } \\
\text { better) }\end{array}$ & $\begin{array}{c}\text { Public } \\
\text { expenditures } \\
\text { (b) } \\
\text { (high score is } \\
\text { better) }\end{array}$ & $\begin{array}{c}\text { Legal } \\
\text { framework } \\
\text { (c) } \\
\text { (high score is } \\
\text { better) }\end{array}$ & $\begin{array}{l}\text { Cardinal ranking } \\
\text { (based on adding } \\
\text { values of a, b } \\
\text { and c) } \\
\text { (1 is best) }\end{array}$ & $\begin{array}{l}\text { Borda ranking } \\
\text { (based on adding } \\
\text { the rankings a, b } \\
\text { and c) } \\
\text { (1 is best) }\end{array}$ \\
\hline India & 0.6 & 0.5 & 0.9 & 1 & 2 \\
\hline China & 0.3 & 0.6 & 0.5 & 3 & 3 \\
\hline Brazil & 0.8 & 0.8 & 0.1 & 2 & 1 \\
\hline
\end{tabular}

developing countries to start a National Programme for Food Security. This indicator looks at the extent to which these are advancing towards implementation.

- Civil registration of births (percentage of population). Public affirmation of an individual's existence from birth (to death) is critical for the effective realisation of legal and civil rights and socioeconomic state provisions (Szreter 2007: 67-8). It enhances access to a range of government services, including health and social protection, that can assist in combating food insecurity.

\section{Public expenditures}

For this theme, the three indicators are:

- Public expenditure on health as percentage of total government expenditure. This indicator acknowledges the importance of a wellfinanced public health system for the prevention of hunger and malnutrition.

- Public expenditures on agriculture as percentage of total government expenditure. Public investment in agricultural systems is critical, as recognised in the African Union's Maputo Declaration (2003), ${ }^{5}$ which aspires for member states to spend at least 10 per cent of government budgets on agriculture.

- Public expenditure on education as percentage of gross domestic product (GDP). This indicator recognises the central importance of education in achieving higher incomes to enhance access to food. ${ }^{6}$

\section{Legal framework}

For this theme, the three indicators are:

- Women's access to agricultural land. If women in rural areas had the same access to land, technology, financial services, education and markets as men, agricultural production could be increased and the number of hungry people reduced by 100-150 million (FAO 2011).

- Constitutional right to social security. The constitutional right to social security signals a clear willingness and strong legal duty for governments to protect their citizens from destitution, and attendant hunger.

- Level of constitutional protection of the right to food. A constitutional right to food provides a very clear signal of government commitment to reduce hunger. This indicator recognises the various ways in which such a right may be incorporated in the highest body of law.

\section{Calculating $\mathrm{HRCl}$ scores and rankings}

The HRCI builds on ActionAid's HungerFREE Scorecard (ActionAid 2009, 2010) to find sufficient data for 21 out of its selection of 29 countries with a substantial hunger problem. We normalise indicator scores to ensure no indicator has greater weight in the determination of the index because of its unit of measurement. Each theme is given equal weight and each indicator is given equal weight within each theme. The HRCI employs a Borda ranking scheme (Table 2) to rank the sum of the rankings rather than the values of the indicators across themes (Dasgupta 2001).

Our sensitivity analyses show the HRCI as robust for our selection of variables, the normalisation method and weighting scheme. High Spearman rank correlations and before/after comparisons demonstrate that country rankings do not vary substantively after making small changes in construction of the index. Table 3 shows countries' overall, and theme-specific commitment rankings.

Malawi tops the HRCI 2011, reflecting breadth of strength across themes. Its top ranking is salient because in the last year, donor support for Malawi has been partially withdrawn, due to a 


\begin{tabular}{|c|c|c|c|c|c|c|}
\hline Country & $\begin{array}{c}\text { Rank: } \\
\text { legal } \\
\text { framework }\end{array}$ & $\begin{array}{c}\text { Rank: } \\
\text { government } \\
\text { expenditures }\end{array}$ & $\begin{array}{l}\text { Rank: } \\
\text { policies and } \\
\text { programmes }\end{array}$ & $\mathrm{HRCl}$ & $\begin{array}{l}\text { Overall } \\
\text { Borda } \\
\text { score }\end{array}$ & $\begin{array}{c}\text { Commitment } \\
\text { level }\end{array}$ \\
\hline Malawi & 2 & 4 & 4 & 1 & 56 & \\
\hline Guatemala & 2 & 15 & 2 & 2 & 47 & \\
\hline Brazil & 1 & 18 & 1 & 3 & 46 & \\
\hline Senegal & 14 & 2 & 7 & 4 & 43 & 'High' \\
\hline Ethiopia & 2 & 3 & 19 & 5 & 42 & \\
\hline Tanzania & 9 & 1 & 14 & 5 & 42 & \\
\hline Ghana & 9 & 7 & 9 & 7 & 41 & \\
\hline Gambia & 2 & 12 & 12 & 8 & 40 & \\
\hline Uganda & 2 & 17 & 10 & 9 & 37 & \\
\hline Rwanda & 20 & 6 & 3 & 9 & 37 & \\
\hline Burundi & 14 & 9 & 6 & 9 & 37 & \\
\hline Nigeria & 2 & 19 & 8 & 9 & 37 & 'Medium' \\
\hline India & 9 & 11 & 11 & 13 & 35 & \\
\hline Kenya & 14 & 13 & 5 & 14 & 34 & \\
\hline Mozambique & 14 & 5 & 13 & 14 & 34 & \\
\hline Bangladesh & 2 & 20 & 20 & 16 & 24 & \\
\hline Lesotho & 19 & 8 & 15 & 16 & 24 & \\
\hline Nepal & 13 & 14 & 16 & 18 & 23 & 'Low' \\
\hline China & 9 & 16 & 21 & 19 & 20 & \\
\hline Zambia & 21 & 10 & 18 & 20 & 17 & \\
\hline Guinea Bissau & 14 & 21 & 17 & 21 & 14 & \\
\hline
\end{tabular}

worsening political climate. Guatemala ranks second overall, performing strongly on the legal framework and policies and programmes themes, yet it does less well on agriculture, health and education spending. Brazil, the overall number three, outperforms Malawi and Guatemala on two themes, but did not top the list due to a low ranking on the government expenditure theme. India is found in thirteenth spot. Had the HRCI been able to include social protection spending (which it could not for lack of comparable data), several countries may have performed better on the government expenditures theme. These include, amongst others, Brazil (e.g. Bolsa Familia), China (dibao) and India (e.g. Mahatma Gandhi National Rural Employment Guarantee Scheme, Public Distribution System). The five worst performing countries in the HRCI are
Guinea Bissau (21), Zambia (20), China (19), Nepal (18), and Lesotho and Bangladesh (shared sixteenth).

Many countries perform highly divergently on the three themes. For instance, Tanzania has the best score on expenditures, but ranks fourteenth on policy. For Brazil, this situation was reversed. Inconsistent performance can have strong effects on overall ranking. For instance, Bangladesh performs less well than Zambia on the themes of policies and programmes and on government expenditures, yet its strong score on legal framework makes it outperform Zambia overall. China does fairly well on legal frameworks, but its weaker scores on policies and programmes and on spending have substantial effect on its remarkably low overall ranking. It should be 


\begin{tabular}{|c|c|c|c|c|c|}
\hline \multicolumn{6}{|c|}{ Hunger status (GHI 2010) } \\
\hline & Low & Moderate & Serious & Alarming & Extremely alarming \\
\hline \multicolumn{6}{|c|}{ Commitment } \\
\hline \multirow[t]{3}{*}{ Low } & & China & Nepal & Guinea Bissau & \\
\hline & & & Lesotho & Zambia & \\
\hline & & & & Bangladesh & \\
\hline \multirow[t]{4}{*}{ Medium } & & & Kenya & India & Burundi \\
\hline & & & Nigeria & Rwanda & \\
\hline & & & Gambia & Mozambique & \\
\hline & & & Uganda & & \\
\hline \multirow[t]{3}{*}{ High } & Brazil & Ghana & Malawi & Ethiopia & \\
\hline & & & Guatemala & Tanzania & \\
\hline & & & Senegal & & \\
\hline
\end{tabular}

noted that China's outstanding hunger outcome reductions over the last decades are not included in the HRCI. This result demonstrates the importance of contextualising commitment: lower commitment is more compatible with (and may be driven by) a smaller hunger problem.

The overall Borda scores in Table 3 show that closeness of ranking may hide dissimilar performances. For instance, Malawi and Guatemala differ one rank, yet Malawi scored nine 'points' higher. Similarly, Mozambique and Bangladesh have just one rank between them, but this reflects ten Borda 'points'. Guatemala and Brazil also differ by one rank, but here this reflects only one Borda 'point'.

How can we relate political commitment scores to hunger outcomes? In order to draw comparison, we group commitment levels by simple reference to the upper, middle and lower third of countries' overall HRCI Borda scores (Table 3). These scores are set out against a country's hunger status, as per the Global Hunger Index (2010 edition)..$^{7}$ This crosstabulation (Table 4) suggests that countries like Malawi, Guatemala, Senegal, Ethiopia and Tanzania may be fruitful contexts for donors to advocate and support hunger reduction efforts, as they are characterised by high commitment and high levels of hunger. India, despite its 'alarming' hunger status, demonstrates only medium levels of political commitment to do something about it. The table also shows countries with low commitment to address a serious or alarming hunger status: Guinea Bissau, Zambia, Bangladesh, Nepal and Lesotho.

In a similar vein, commitment levels can be set off against the ability of state and non-state actors to act on hunger, as for instance expressed by wealth, state administrative capacity, and public accountability (te Lintelo et al. 2011).

\section{Expert perceptions of political commitment} Complementing the HRCI rankings, we employed a structured survey to capture primary data on commitment. Thirty Zambian and 45 Bangladeshi experts on hunger and malnutrition (representing government, academic, private sector, donors, and civil society) were asked to indicate their level of agreement with statements and questions designed to capture a number of commitment indicators (Brinkerhoff 2000: 2):

- The institutionalisation of credible incentives for individuals (in) and between government agencies (e.g. is poor performance on hunger objectives sanctioned, and success rewarded?)

- Institutional policy coordination

- Locus of policy origin (e.g. is the implementing agency the one that designed policy, having strong ownership?)

- Learning and adaptation mechanisms and practices (e.g. regular monitoring and evaluation $[\mathrm{M} \& \mathrm{E}])$ 


\begin{tabular}{lll}
\hline \multicolumn{2}{l}{ Table 5 Expert survey scores on commitment indicators: Bangladesh and Zambia (mean scores) } \\
\hline Indicator & Bangladesh & Zambia \\
\hline Institutional coordination & 2.37 & 2.19 \\
Government intention and action & 2.34 & 2.01 \\
Locus of initiative & 2.42 & 1.79 \\
Analytical rigour & 2.50 & 1.94 \\
Learning and adaptation & 3.05 & 2.96 \\
Public commitment & 3.06 & 2.49 \\
Mobilisation of stakeholders & 3.11 & 3.00 \\
Continuity of effort & 3.32 & 2.99 \\
Credible incentives & 3.90 & 4.45 \\
\hline Overall score & $\mathbf{2 . 9 1}$ & $\mathbf{2 . 6 5}$ \\
\hline
\end{tabular}

Note 1 = highest commitment; 5 = lowest commitment to hunger reduction

- Evidence in decision-making processes (e.g. is policy informed by new insights on how to address hunger?)

- Mobilisation of stakeholders (e.g. how well do government agencies act to obtain widespread support for interventions?)

- Public commitment (are decision-makers' policy preferences revealed?)

- Resource allocation and expenditures (e.g. what is the strength, relevance and sufficiency of spending on hunger reduction policies?)

- Continuity of effort (e.g. are efforts strong and sustained, or one-shot efforts?)

Five-point Likert scales ( 1 = very strongly, $2=$ strongly, $3=$ moderately, $4=$ weakly, $5=$ very weakly) were used to calculate indicator and aggregate scores for the group of experts. As the same score may mean different things in different countries, we do not make cross-country comparisons. The survey instrument, however, has four advantages: (1) applied regularly, it is more sensitive to changes in political commitment than secondary data; (2) it can be adjusted to a country's circumstances; (3) it captures insightful data not expressed in existing data sources that (4) may inspire expert networking, initiate dialogue, raise awareness and foster new action to enhance political commitment to hunger reduction. While perception surveys may draw criticism for being subjective and unable to express 'true' commitment levels, this merely underlines the need for having 'objective' data. Good data should not be the enemy of (non-existent) best data.

Table 5 summarises overall findings for Zambia and Bangladesh.

The experts assessed that relative to other dimensions, Bangladesh and Zambia score quite strongly in terms of institutional coordination, to challenge international discourses that often argue the opposite (e.g. Chopra et al. 2009; Engesveen et al. 2009). Both countries are judged to do (reasonably) well in terms of locus of initiative, and analytical rigour underlying policy efforts, and gained moderate scores for learning and adaptation, mobilisation of stakeholders and continuity of effort. Expert opinions further highlight that weak institutional incentives for civil servants and government bodies hinder efforts to combat hunger. The expert survey thus enables a diagnosis of commitment aspects on which governments do better or worse, to suggest to both governments and advocacy groups what areas require additional attention to accelerate hunger and malnutrition reduction.

\section{Conclusions}

Food justice demands better governance and greater government accountability. The HRCI offers innovative instruments to assess governments' political commitment to reduce hunger and malnutrition reduction. It measures and ranks countries' actions towards enhancing 
food availability, access and utilisation, as expressed in policies and programmes; public expenditures; and legal frameworks.

Malawi, Guatemala, Brazil, Senegal and Ethiopia head the HRCI 2011 rankings, with Lesotho, Nepal, China, Zambia (20th) and Guinea Bissau coming bottom. India occupies a thirteenth position, with a medium level of political commitment.

Cross-tabulating political commitment levels against variables such as hunger status can provide strategic guidance to governments, civil society, donors, and other stakeholders as to where their efforts can make the biggest difference. The expert survey instrument helps to identify on what

\section{Notes}

1 This article is based on research supported by Irish Aid.

2 For a review of their qualities and weaknesses, see Masset (2011).

3 This indicates those people contributing to developing the HRCI.

4 The HRCI produces two indices: one for developed (donor), another for developing countries; this article focuses on the latter.

5 See www.nepad.org/system/files/Maputo\%20 Declaration.pdf.

\section{References}

ActionAid (2010) Who's Really Fighting Hunger?, HungerFREE Scorecard 2010, London: ActionAid

ActionAid (2009) Who's Really Fighting Hunger?, HungerFREE Scorecard 2009, London: ActionAid

Brinkerhoff, D.W. (2007) 'Where there's a Will, there's a Way?', The Whitehead Journal of Diplomacy and International Relations Winter/Spring: 111-20

Brinkerhoff, D.W. (2000) 'Assessing Political Will for Anti-corruption Efforts: An Analytic Framework', Public Administration and Development 20.3: 239-52

Chopra, M.; Pelletier, D.; Witten, C. and Dieterich, M. (2009) 'Assessing Countries' Readiness: Methodology for In-depth Country Assessment', SCN News 37: 17-22

Dasgupta, P. (2001) Human Well-Being and the Natural Environment, New York: Oxford University Press

Engesveen, K.; Nishida, C.; Prudhon, C. and Shrimpton, R. (2009) 'Assessing Countries' commitment aspects governments perform weakly, and on which they do well and deserve praise.

In coming years, the HRCI process will conduct regular surveys in a growing number of countries. India is a priority, and new research will be conducted at national and state levels. Econometric methods will be used to see if the HRCI has potential to accelerate hunger reduction, and community voices engaged to extend ownership and to gain an additional 'expert' perspective on government commitment. Moreover, we will assess whether, and if so how, the HRCI process can support greater advocacy efforts to reduce hunger and malnutrition.

6 Data on government spending on education as a share of total government expenditures was not available (for the same years as on agriculture and health), and are thus presented as share of GDP. No comparable data on social protection spending could be identified.

7 See www.ifpri.org/publication/2010-globalhunger-index.

Commitment to Accelerate Nutrition Action Demonstrated in PRSPs, UNDAFs and through Nutrition Governance', SCN News 37: 10-16

FAO (2011) The State of Food and Agriculture Women in Agriculture - Closing the Gender Gap for Development, Rome: Food and Agriculture Organization

Haddad, L.J. (2009) 'Lifting the Curse: Overcoming Persistent Undernutrition in India', IDS Bulletin 40.4: 1-8

Hammergren, L. (1998) Political Will, Constituency Building, and Public Support in Rule of Law Programs, Washington DC: United States Agency for International Development (USAID)

Masset, E. (2011) 'A Review of Hunger Indices and Methods to Monitor Country Commitment to Fighting Hunger', Food Policy 36 Supplement 1: S102-S108

Mohmand, S.K. (2011) Analysing Nutrition Governance - India Country Report, Brighton: IDS: 17

Morrissey, O. and Verschoor, A. (2006) 'What does Ownership mean in Practice? Policy Learning and the Evolution of Pro-Poor 
Policies in Uganda', in A. Paloni and M. Zanardi, The IMF, World Bank and Policy Reform, London: Routledge

Szreter, S. (2007) 'The Right of Registration: Development, Identity Registration, and Social Security - A Historical Perspective', World Development 35.1: 67-86

te Lintelo, D.J.H.; Haddad, L.J.; Leavy, J.; Masset, E. and Stanley, A. (2011) Measuring the
Commitment to Reduce Hunger: The Hunger Reduction Commitment Index, Brighton: IDS

The Policy Project (2000) HIV/AIDS Toolkit Building Political Commitment, Washington DC: The Policy Project

Thomas, J.W. and Grindle, M.S. (1990) 'After the Decision: Implementing Policy Reforms in Developing Countries', World Development 18.8: 1163-81 